\title{
DIALÉTICA, PARADOXO E O ENIGMA DO HOMEM EM PASCAL
}

\author{
Antonio Mauro Muanis de Castro*
}

SÍNTESE - Este artigo aborda a questão da dialética nos paradoxos enunciados por Blaise Pascal. Após fazer alusão ao início da dialética na Grécia antiga, o trabalho se desenvolve com a tematização das categorias utilizadas por Pascal, tais como: coração-razão, infinito-finito, grandeza-miséria, que apontam, em última instância, para o caráter insolúvel do enigma sobre 0 mundo, a vida e o ser humano.

PALAVRAS-CHAVE - Pascal, dialética, paradoxo, enigma do homem.

\begin{abstract}
This article approaches the subject of the dialectic in the paradoxes statements for Blaise Pascal. After doing allusion to the beginning of the dialectic in oid Greece, the work develops with the tematização of the categories used by Pascal, such as: heart-reason, infinitefinite, greatness-poverty, that they point, ultimately, for the insoluble character of the enigma on the world, the life and the human being.

KEY WORDS - Pascal, dialectic, paradox, the man's enigma.
\end{abstract}

Estaria a dialética habilitada a explicar o paradoxo do homem com o mundo, com a realidade e com Deus? Como entender a dialética nos paradoxos enunciados por Pascal, quando este se detém na análise do enigma do homem; um ser que pensa e que sonha, que ri e que chora, que ama e que odeia, que vê em si grandeza e miséria, que espera e desespera.

Dialética, termo que ainda não foi desapropriado da filosofia, embora tenha percorrido a intimidade dos processos históricos, idealistas e materialistas, e perambulado pelos discursos ideológicos.

Como entender a dialética? Seria ela apenas um método ou também uma realidade?

O movimento dialético parece presente no progresso das ciências naturais, da economia, da política, da técnica, da comunicação, da informática, perfazendo um processo na história da cultura e da humanidade.

De Platão a Hegel se renovam as versões da rèlação Heráclito e Parmênides, em que a mediação histórica comprova o sucesso do processo dialético. A realidade é dinâmica e estática ao mesmo tempo. Para entendê-la, é imprescindível o método dialético. Heráclito e Parmênides, a rigor, nada disseram de contrário ou

* Universidade Gama Filho - Rio de Janeiro.

\begin{tabular}{|l|l|l|l|l|l|} 
VERITAS & Porto Alegre & v. 43 & $n^{2} 4$ & Dezembro 1998 & p. 979-983 \\
\hline
\end{tabular}


de contraditório. Aquele como tese, este como antítese, suscitam já em Platão e Aristóteles uma síntese, sendo que este último se converte em antítese de Platão.

O monismo dinâmico registrava o aspecto mutável da realidade que juntamente com o monismo estático seria sintetizado em Platão através da teoria das idéias, enquanto que em Aristóteles se converteria no hilemorfismo, sistema que procurou converter os dois monismos em um realismo unitário. Os dois realismos, dualista e unitário, são a síntese das Escolas de Éfeso e de Eléia.

Importa, pois, antes de tudo, contextualizar e conceituar a dialética. Dia + 1ogos, dia + legein ou ainda dia + lekticos, apreendendo os significados de: através do pensamento, palavra, reciprocidade, mutualidade de pensamento, de argumentação, ou ainda, disputa, discussão.

Se nos inspirarmos em Sócrates, o dia + logos teria duas acepções: a primeira, seria uma argumentação de esclarecimento para os amigos incorporando-lhes novos conhecimentos ou deles absorvendo o saber de que eram portadores; a segunda, uma outra forma de argumentação, visava a incomodar seus adversários com objeções e negações sobre o ponto-de-vista estabelecido, convertendo assim o diálogo em debate, disputa ou discussão e através de contradições incorporar do outro o ponto de vista de que necessita. Na primeira atitude de Sócrates, estaria presente o diálogo, uma reflexão entre amigos; na segunda, no entanto, notarse-ia a dialética, onde o conflito de idéias estaria estabelecido.

É nestes termos que a realidade, a vida e o conhecimento se encontram, conforme avaliação de Pascal:

"As ciências [diz ele] têm duas extremidades que se tocam. A primeira é a ignorância natural em que se acham todos os homens ao nascer. A outra é a extremidade a que chegam as grandes almas, as quais, tendo percorrido tudo o que os homens podem saber, verificam que não sabem nada e se descobrem nessa mesma ignorância de que partiram" (Pascal, 196, p. 327).

É nesta esteira que Pascal prossegue seu pensamento, como que em uma auto-maiêutica, sendo seus interlocutores os enigmas do homem, da vida e da realidade. Assim soa "o silêncio eterno destes espaços infinitos." (Pascal, 1961, p. 105).

Na dialética gravitam dois sujeitos que se debatem em constantes transações de opiniões, em torno de um objeto. Em Pascal, o objeto se duplica em posições paradoxas, como que provocando o sujeito. É o que diz Kierkegaard referindo-se à verdade;

\footnotetext{
“eia é essencialmente dialética: implica o diálogo comigo mesmo, ou seja, o ato pelo qual eu elaboro a minha própria verdade, quando a assumo, e me crio a mim mesmo na ação, e implica ainda o estado de tensão que em mim provoca o risco que qualquer compromisso sério envolve sempre" (Jolivet, 1975, p. 46-47).
}

A complexidade do mundo, da vida e do homem necessita de um método ou processo lógico que tenha sintonia com a realidade. Por isso é que se nota, nas mais variadas expressões da filosofia, a dialética sendo identificada quer com a realidade, quer com os processos que a pesquisam. Para Aristóteles é uma forma não demonstrativa do conhecimento, mais próxima da disputa e da probabilidade, que dá ensejo ao "silogismo" eristico. 
A adoção de um recurso que reunisse teses opostas fez Abelardo do sic et non um método crítico da escolástica, no qual reúne autoridades teológicas e bíblicas em aparente contradição, a fim de buscarem conciliação e transferir para os ouvintes e interlocutores os encargos de decidirem sobre a verdade. No século XII, a dialética era entendida, ora como arte de raciocinar, ora como argumentação sofística contra a fé.

Nova versão da dialética irá ocorrer, quando a expressão dogmática do conhecimento entra em crise, exigindo da filosofia maiores cuidados em suas conclusões sobre a verdade. Não só a dúvida metódica passa a ser necessária como também a própria razão perde sua hegemonia enquanto fonte de todo conhecimento.

Amargas são as referências dirigidas a Descartes por Pascal. "Descartes: inútil e incerto. [...] não acreditamos que toda a filosofia valha uma hora de trabalho" (Pascal, 1961, p. 72). A dialética entre a razão e o "coração" fez com que David Hume despertasse Kant, em Königsberg, do sono dogmático. A dúvida se instalara no santuário da razão, e Kant se aplica na análise dos limites do conhecimento. A metafísica perde suas características clássicas e a dialética ganha um lugar especial nas reflexões kantianas. Na segunda divisão da lógica transcendental, Kant denomina-a de lógica da aparência, ilusão transcendental ou ainda dialética transcendental. Aparência dos paralogismos que provêm unicamente de uma falta de atenção à regra lógica. Diz Kant:

\begin{abstract}
"A dialética transcendental deverá pois contentar-se com descobrir a aparência de juizos transcendentes, evitando ao mesmo tempo que esta aparência nos engane; mas nunca alcançará que essa aparência desapareça (como aparência lógica) e deixe de ser aparência. Pois trata-se de uma ilusão natural e inelutável, assente aliás, em princípios subjetivos, que apresenta como objetivos, enquanto a dialética lógica, para resolver os paralogismos, apenas tem de descobrir um erro na aplicação dos principios, ou uma aparência artificiai na sua imitação. Há pois uma dialética da razão pura natural e inevitável; não me refiro à dialética em que um principiante se enreda por falta de conhecimentos, ou àquela que qualquer sofista engenhosamente imaginou para confundir gente sensata, mas à que está inseparaveimente ligada à razão humana e que, descoberta embora a ilusão, não deixará de The apresentar miragens e lançá-la incessantemente em erros momentâneos, que terão de ser constantemente eliminados" (Kant, 1985, p. 297-298).
\end{abstract}

É, portanto, a lógica da aparência, o que parece ser. Não a lógica do ser em si, mas a lógica do ser em nós. Uma ilusão em nós, do em si, que nos apavora, diria Pascal.

A insuficiência da dialética faz dela ä expressão de um conteúdo aberto, não acabado, não dogmático, como propõe Adorno na Dialética dọ esclarecimento:

"A Dialética do Esclarecimento foi concebida com o ambicioso propósito de 'descobrir por que a humanidade, em vez de entrar em um estado verdadeiramente humano, está afundando em uma nova espécie de barbárie.' $[\ldots]$ 'O horror que um dia culminou em Auschwitz operou com uma lógica imanente ao espirito: a regressão deste" (Barbosa, 1996, p. 40).

Método que diante dos paradoxos exige a incorporação da ilusão do outro, por isso qualquer que seja o conteúdo, este deverá sempre ser aberto. 
Como precisar a dialética, onde ela se situa? No objeto, na relação sujeitoobjeto, ou simplesmente no sujeito? Ou ainda, não seria a dialética o instrumento que desataria os enigmas, ou a senha que abriria o sistema?

Sem recorrermos novamente a Kant, podemos afirmar que os paradoxos existentes sobre a existência, a vida e o homem precisam ser enfrentados. E mesmo conscientes da ilusão transcendental podemos reconhecer que algo de novo deve surgir como produto de uma sensibilidade dialética.

O paradoxo mais radical, que toca a sensibilidade dialética do homem, é aquele que tenta em vão provar ou negar a existência de um Deus. Aos crentes e ateus "Deus se ocultou ao conhecimento deles, a ponto de nomear-se a si próprio, nas Escrituras, Deus absconditus, Isaias, XIV, 15" (Pascal, 1961, p. 98). Não bastando este item, próprio da dialética transcendental, Pascal cita outro de igual relevância e tão paradoxal quanto o primeiro:

\begin{abstract}
"A imortalidade da alma é uma coisa que nos interessa tanto, que nos toca tão profundamente, que seria preciso ter perdido todo sentimento para deixar-se ficar indiferente, sem saber o que há a respeito. Todas as nossas ações e pensamentos seguem caminhos tão diferentes, conforme haja ou não bens etemos a esperar, que é impossível tentar alguma coisa com sentido e juízo, sem regulá-la pela mira deste ponto, que deve ser o nosso último objetivo" (Pascal, 1961, p. 99).
\end{abstract}

Continua apontando como dever do homem esclarecer um assunto do qual depende toda a sua conduta. Aqui Pascal e Kant se aproximam; aquele com as razões do "coração", este com a razão pura prática. A fé, gerada pelas razões do "coração" e a religião que surge da dialética dos costumes (Kant, KpV, 1997, p. 155). Para Pascal, Deus se mantém escondido, oculto ao conhecimento humano pela insuficiência da própria razão, tornando a fé necessária e superior à própria razão. Em Kant, respeitando os limites da razão, o espaço concedido ao entendimento se encerra na Analítica Transcendental. Na Dialética Transcendental, assim como na Metafisica dos Costumes, a razão estará desprovida de todo conteúdo empírico, sendo este substituído por uma "antropologia prática" o que lhe fará convir o nome de "ilusão transcendental" (Kant, FMC, 1983, p. 16). Assim sendo, aquilo que escapa à condição da ciência cai no campo da fé, objeto da dialética transcendental, como os postulados da razão prática; a existência de Deus e a imortalidade da alma, verdades percebidas exclusivamente pelo "coração".

"Aparentemos a coragem que quisermos, qual é o fim que espera a mais bela vida do mundo" (Pascal, 1961, p. 100)? Coragem, desespero e esperança se alternam dialeticamente sem que se possa perceber qual a tese, a antítese ou a sintese. Sem saber de onde veio, não sabe também para onde irá. Incoerência trágica que afeta o único ser que sabe que morre, mas não sabe por que morre.

Quem é o homem afinal? Responde Pascal:

"Nada em relação ao infinito; tudo em relação ao nada; um ponto intermediário entre o tudo e o nada. Infinitamente incapaz de compreender os extremos, tanto o fim das coisas como o seu princípio permanecem ocultos num segredo impenetrável, e é-lhe igualmente impossivel ver o nada de onde saiu e o infinito que o envolve" (Pascal, 1961, p. 66). 
Somos seres perdidos no espaço e no tempo. Que dialética poderá explicar o motivo que fez com que ocupássemos este lugar e não outro na vastidão do universo? Como entender a curta duração da minha vida situada entre uma eternidade que a precedeu e outra que a seguirá? Nada entendemos acerca da infinidade que nos envolve. "Por ordem e mandato de quem me foi designado este lugar e este tempo? [...] O silêncio eterno desses espaços infinitos me apavora" (Pascal, 1961, p. 105).

Na dialética do tempo e da eternidade seguimos os ditames do "coração" que nos aponta a eternidade, enquanto a razão nos limita à temporalidade. "CoraÇão" e razão não se entendem no paradoxo das opções.

O homem é a sintese mais paradoxal da natureza; une inexplicavelmente: 0 ser e o não-ser, o bem e o mal, o nada e o tudo, o belo e o feio, a verdade e a falsidade, grandeza e miséria, corpo e espírito, amor e ódio. A fragilidade do "caniço pensante" sente toda a sua dignidade no fato de pensar, enquanto se confronta com a grandeza brutal de um mundo que não pensa. Na dialética entre a grandeza e a miséria, "o homem sabe que é miserável [...] de vez que o é; mas é bem grande de vez que o sabe."

Retornemos ao mais radical dos paradoxos. Pela argumentação de Parmênides, sabemos que o pensamento grego não concebe a existência do nada, admitindo a eternidade tanto para as idéias, como para a matéria, sem concluir sobre a existência do princípio (arqué).

Paradoxalmente, a fé cristã afirma que o princípio é Deus, do qual tudo teve sua origem.

A que dialética recorrer para resolver este impasse? Não sendo possível provar em uma coisa, nem outra, o enigma sobre o mundo, a vida e o homem permanece insolúvel. Qualquer síntese parece impossivel.

É necessário apostar, diz Pascal:

"Examinemos pois este ponto e digamos: Deus existe ou nâo existe? Para que lado ncs inciinaremos? A razão não o pode determinar: há um caos infinito que nos separa. Nessa extremidade infinita joga-se cara ou coroa. Em que apostareis? Pela razão não podereis átingir nem uma coisa nem outra. [...] é preciso apostar [...] Pesemos o ganho ou a perda escoIhendo que Deus existe. Consideremos estes dois casos: se ganhardes, ganhareis tudo; se perderdes, não perdereis nada. Apostai pois que ele existe, sem hesitar" (Pascal, 1961, p. 99).

\section{Referências bibliográficas}

PASCAL, Blaise. Pensamentos. São Paulo: Difusão Européia do Livro, 1961.

KANT, Immanuel. Fundamentación de la Metafisica de las Costumbres. Madrid: Espasa-Calpe, 1983.

. Crítica da razão pura. Lisboa: Fundação Calouste Gulbenkian, 1985.

- Critica de la razon practica. Salamanca: Sígueme, 1997.

JOLIVET, Régis. As doutrinas existencialistas. Portc: Tavares Martins, 1975.

BARBOSA, Ricardo Corrêa. Dialética da reconciliação. Rio de Janeiro: UAPE், 1996. 